\title{
Enhance your CQ as well as IQ, EQ \& SQ
}

\section{Thakar $\mathrm{K}^{*}$}

Education department, Veer Narmad South Gujarat University, India

*Corresponding author: Thakar K, Associate professor, Education department, Veer Narmad South Gujarat University, Surat, India, Email: kirtimatliwala8@gmail.com

\section{Review Article}

Volume 6 Issue 1

Received Date: January 04, 2022

Published Date: February 07, 2022

DOI: $10.23880 / \mathrm{mhrij}-16000159$

\section{Abstract}

We are much interested for our consciousness because our happiness and success are relying on it. But what is consciousness? Consciousness is a state of awareness. Awareness of our external situation in relation to the internal .The awareness is the light which reveals the contents of our inner and outer world and the energy find its expression through the faculties and instruments of our consciousness. Brazdau $\mathrm{O}$ [1] has defined consciousness as "the level of consciousness (or the level of being conscious) that is experienced in the morning, $1 / 2-1$ hour after we are awake, after a refreshing sleep, without being exposed to any significant stimulus such as coffee, TV, radio, music or talking." The Consciousness Quotient is related with six primary factors:

- $\quad$ Physical Consciousness

- $\quad$ Emotional Consciousness

- $\quad$ Mental (Cognitive) Consciousness

- Spiritual Consciousness

- $\quad$ Social-Relational Consciousness

- $\quad$ Self-consciousness.

According to Brazdau 0, et al. [2] some other secondary factors of the Consciousness Quotient are

- Internal State Awareness

- $\quad$ Self- Reflectiveness

- Mindfulness

- Autonomy

- $\quad$ Personal Growth

- $\quad$ Positive Relations with Others

- $\quad$ Purpose in Life

- Verbal Expression

- Openness toward new experiences.

In present paper researcher has focused on importance of CQ as well as IQ, EQ and SQ.

Keywords: CQ; IQ; EQ; SQ

Abbreviations: EQ: Emotional Quotient; IQ: Intelligence Quotient; SQ: Spiritual Quotient; CQ: Consciousness quotient. 


\section{Mental Health \& Human Resilience International Journal}

\section{Introduction}

We are living in new era which is technology based. We have many sources for knowledge to update ourselves according to the technology. We are much busy in our daily life with technology. We do our work effectively but we are not much aware about action. IQ gives us intelligence but does not awareness. But what is consciousness? Consciousness is a state of awareness. Awareness of our external situation in relation to the internal .The awareness is the light which reveals the contents of our inner and outer world and the energy find its expression through the faculties and instruments of our consciousness.

\section{Rational of the study}

Researchers from psychology and neurosciences have been becoming interested in studying consciousness as a research variable [3], which is trying to explore and to measure it. In the same time research on conscious self, as a topic of cognitive psychology become important for researchers [4]. Currently there are many approaches in neurosciences trying to capture the essence of consciousness processes [5]. However, psychology, specifically psychological assessment, lacked until recently a complex instrument that is trying to capture and measure different areas of conscious awareness. Brazdau O [6] developed the Consciousness Quotient Inventory and established initial psychometric properties [2].

\section{Objectives}

The study was conducted with the following objectives:

- To study the intelligent quotient, emotional quotient, spiritual quotient and consciousness quotient.

- To study the way for enhancement of consciousness quotient.

\section{Methodology}

The study was carried out on lines of the qualitative research method.

\section{Sample}

Present study is conducted by qualitative research method so researcher has used literature regarding IQ, EQ, $S Q$ and CQ. Thus these literatures are included in the sample for the study.

\section{Tools}

This is qualitative research so documents are used as the tools for the study.

\section{Data Interpretation}

\section{IQ, EQ and SQ}

We have seen in our daily life that IQ does not predict happiness. Our happiness is relying on our emotional intelligence (EQ) and spiritual intelligence (SQ). We can measure our IQ easily but EQ \& SQ both are extremely hard to measure.

\section{IQ-Intelligence Quotient}

IQ is about our thinking. It measures our cognitive ability but academic or cognitive intelligence alone offers little preparation for the emotional challenges we all have to face in our daily lives.

\section{EQ-Emotional Quotient}

EQ is about feeling. It is a term used to represent factors that can lead us to healthy relationships. It is represent our ability to respond appropriately and positively to our everyday life situations. It is about recognizing emotions and managing them. EQ is about understanding ourselves, how we relate to others and how others perceive us. EQ also helps us to understand how others are feeling and enables us to develop more fulfilling and deeper relationships.

\section{SQ-Spiritual Quotient}

SQ is very difficult to define. It is not about organized religion only. One of the biggest qualities of SQ is wisdom. $\mathrm{SQ}$ is related with values such as courage, integrity, intuition, compassion, empathy and knowing the limits of our knowledge. It is about questioning life issues; thinking outside the box; seeing situations and issues differently; having a greater understanding of all possibilities. Spirituality is an essential component of a holistic approach to life. Spirituality sustains us from within when all else fails; spirituality allows us to dream, aspire and raise ourselves up. Thus, while computers have IQ and animals can have EQ, it is essentially an SQ that sets human beings apart. Therefore, for the 'Wheel of Life' to roll smoothly, all the spokes of the wheel - IQ, EQ and SQ - have to be equally developed. The journey from IQ to $S Q$ represents moving from gross to subtle, finite to infinite and from tangible to intangible.

\section{Consciousness Quotient (CQ)}

Consciousness: No aspect of human mind is as complex, puzzling, mysterious and indefinable as is consciousness. As Baars BJ [7] puts it, "Consciousness seems to be the biggest and loudest phenomenon we can possibly study, as it is the study of human mind by the human mind". In its simplest 


\section{Mental Health \& Human Resilience International Journal}

form, Velman M [8] considers consciousness in everyday life as presence or absence of experiences. According to him, if phenomenal content (experience) is present, the person is conscious and if phenomenal content is absent the person is not conscious. Baars BJ [3] defines the conscious processes as events that can be reported and acted upon with verifiable accuracy under optimal reporting conditions (minimum delay between event and report).

Consciousness has only recently emerged as a psychological variable and the consciousness quotient (CQ) theory and consciousness quotient inventory are latest arrivals in the theory of consciousness [1], as cited in Brazdau 0 [2]. Brazdau 0 [2] defines consciousness quotient as the general level of being conscious/aware throughout a day, in regular life conditions. The Consciousness Quotient is related with six primary factors:

- Physical Consciousness

- Emotional Consciousness

- Mental (Cognitive) Consciousness

- Spiritual Consciousness

- Social-Relational Consciousness

- Self-consciousness.

According to Brazdau 0, et al. [2] some other secondary factors of the Consciousness Quotient is,

- Internal State Awareness

- Self- Reflectiveness

- Mindfulness

- Autonomy

- Personal Growth

- Positive Relations with Others

- Purpose in Life

- Verbal Expression

- Openness toward new experiences

\section{How CQ can be Enhancing?}

Knowledge, talent and skill are the source of productivity and performance of an individual. But what is not fully recognized in our educational system is that behind outer forms of knowledge, talent or skill, there are corresponding inner faculties of consciousness, which are their psychological source. They are as highly developed intellectual, scientific and intuitive faculty of knowledge, well-developed pragmatic and executive faculty of action. For maximizing the performance of individuals we have to identify these inner psychological faculties and develop all its potentials consciously through appropriate methods. Some of these faculties develop partially in the course of study, work and action. If we do academic, scientific, philosophical, mathematical studies, research or work, we develop our rational, analytical and conceptual intelligence.
Similarly by technological, managerial, professional and entrepreneurial work, we develop the pragmatic intelligence [9]. But if we can supplement this externalized process by a more inward, direct, psychological process so that our inner faculties of knowledge, feeling and action are consciously and systematically activated and developed to their highest potential. So it may possibly lead to a fuller and more accelerated development of our productive capacities. To raise our consciousness quotient, there are some actions which can be used every day. If you bear in mind that the key to consciousness is awareness, because with greater awareness you have greater choice, then consciousnessraising efforts are geared to help you become aware of and step away from your automatic programmes and reactions which trap you into habitual ways of responding, enjoying greater freedom of action, choice and information as a result. For the leader, the potential advantages of this are obvious.

\section{Regular Check Your Body, Mind and Emotions Several Times a Day}

Becoming present - presence being a term for describing being in the here-and-now, not carried away by your thoughts or emotions or lost in other mental activity. Meditation techniques teach this skill of becoming present. Several momentary checking per day is as effective as one long meditation session.

\section{Observation of Reaction}

Observing our reactions to situations from a mental'armslength' and acknowledging that these reactions are attempts to control a situation or to survive - psychologically speaking. We often observe our activity partially unconsciously. Being more conscious doesn't imply that we give up our ability to take action or make choices, but rather that we do this through conscious choice instead of unconscious, automatic programming or reaction to our circumstances.

\section{Seek Feedback from Dear Ones}

This feedback adds to your self-awareness. Feedback takes you usefully into the territory of that which you didn't know that you didn't know about yourself.

\section{Pursue Actuality}

It makes acting powerfully more difficult because we try to effect change based on our interpretations, judgments and denials connected to circumstances. Better to accept and work with the material facts of what is actually true in this moment, without resisting them, denying them or deluding ourselves about them. 


\section{Mental Health \& Human Resilience International Journal}

\section{Assumption Alert}

Being on our toes about the assumptions we make and making a point of delving deeper to check in with information at source. It can be listening to our own intuitive feeling and observing the assumptions we make.

\section{Decrease 'Drag'}

One way of doing this is to carry out a broad scan of everything living within your awareness that feels incomplete, is nagging you or for which you feel guilty. And then take action to complete these items [10].

\section{Practice Abundance}

Choose to practice and experiment with an abundant mindset: that there is enough to go around, that giving is a better practice than taking, and that giving out rather than hoarding (money, information, accolades) tends to encourage circulation of the same, including back to you. Experiment and see what happens.

\section{View Relationships as Mirrors}

To develop your relationship consciousness, practice viewing others as a mirror of yourself in such a way that what you see in them may be a reflection of you demonstrated in your interactions with them.

\section{Oneness}

When the barriers (mental and emotional habits) that cause us to feel separate from and unaffected by others are decreased, we naturally experience a greater sense of connectedness with all things. The greatest practice to develop a sense of oneness is meditation.

\section{Allow your Emotions to Breathe}

One way of growing more conscious is to acknowledge and express your denied and judged feelings and to give space to these feelings through verbal expression, experiencing yourself moving through your internal judgments and walls of fear and shame. Consider that denied aspects of ourselves take up space in our consciousness and continue to be part of us, while we use up the energy of consciousness to keep them hidden, from ourselves and from others.

\section{Conclusion}

We should design activities for enhancement of consciousness quotient. For successful life we should focus on CQ as well as IQ EQ, SQ. We have to spend time for checking ourselves in day to day life. We should give space for breathing of our emotions. Thus we can develop our potential with CQ.

\section{References}

1. Brazdau O (2008) Research on the consciousness experience. The Consciousness Quotient and CQ Inventory. Doctoral dissertation, Romanian Academy of Science, Bucharest, Romania.

2. Brazdau O, Mihai C (2011) The Consciousness Quotient: a new predictor of the students' academic performance. Procedia Social and Behavioral Sciences 11: 245-250.

3. Baars BJ (2003) Introduction: Treating Consciousness as a variable: The fading taboo. Upaya Zen Center.

4. Vasile C (2011) Identity Structures dynamics in adults and elderly people. Procedia Social and Behavioral Sciences 30: 1826-1830.

5. Dehaene S (2001) The Cognitive Neuroscience of Consciousness. Cambridge, Mass: MIT Press.

6. Brazdau O (2013) The Consciousness Quotient: introducing the consciousness experience as a research variable in psychological assessment.

7. Baars BJ (1997) In the Theatre of Consciousness; The global workspace of mind. Journal of Consciousness Studies 4(4): 292-309.

8. Velman M (2009) How to define consciousness and how not to define consciousness. Journal of Consciousness Studies 16(5): 139-156.

9. Baars BJ, Banks WP, Newman JB (2003) Essential Sources in the Scientific Study of Consciousness. Cambridge, Mass: MIT Press.

10. Brazdau 0, Opariuc CD (2014) Preliminary development of the Consciousness Quotient Inventory (CQ-i): introducing the conscious experience as a research variable in psychological assessment. Procedia Social and Behavioral Sciences 127: 600-605. 